\title{
Primary care mental health - A new direction?
}

\author{
Vincent Russell, Martina Kelly
}

Ir J Psych Med 2010; 27(2): 63-65

Current health policy in Ireland, as articulated in the HSE's Transformation Programme (2007-2010), has a focus on the health and wellbeing of the whole population and demands a shift from the hospital system to the primary care setting as the central locus of service delivery. ${ }^{1}$ The main vehicle for this change is the Primary Care Strategy (2001) which recommended the establishment across the country of primary care multidisciplinary teams (PCTs) supported by specialist services in primary care networks (PCNs). ${ }^{2}$ The Primary Care Strategy and Transformation Programme documents both emphasise that successful implementation depends on close liaison and integration between PCTs and networks and secondary care services so that the patient journey from one service to the next is "seamless and delay free".

Consistent with the broad thrust of the national health strategy, the Vision for Change (2006) policy framework for mental health services makes the ambitious statement that it is not enough for a comprehensive mental health policy to make recommendations relating solely to specialist mental health services - it must also deliver mental health activities capable of improving the wellbeing of the population as a whole. $^{3}$

However, while Vision for Change recommends that links between specialist mental health and primary care services should be enhanced and formalised, most of its recommendations relate specifically to specialist mental health service provision. It envisaged that multidisciplinary community mental health teams (CMHTs) occupy community mental health centres in proximity to other community services, but did not go as far as to recommend the actual co-location of CMHTs and PCTs. In a significant recent development, the HSE has now committed to the provision of physical space to accommodate community mental health teams (CMHTs) and day hospital services within all primary care health centres as the Primary Care Strategy is rolled out nationally.

This decision represents a potential milestone in the evolution of mental health service delivery. It presents particular challenges to the historic relationship between primary care and specialist mental health services both of which have been relatively underdeveloped in Ireland, have evolved separately and between which deficiencies in communication and collaboration have been reported by service users and providers alike..$^{4,5}$

*Vincent Russell, MSc, MRCPsych, PRCPC, Consultant Psychiatrist, Cavan General Hospital, Cavan, Ireland. Email: vincentrrussell@hotmail.com

Martina Kelly, MA, MICGP, Park Family Practice, Lower Friar's Walk, Cork, Ireland.

${ }^{\star}$ Correspondence

SUBMITTED: APRIL 19, 2010. ACCEPTED: APRIL 26, 2010.
While the health strategy documents describe overall structures designed to increase primary care capacity and improve integration between primary care and secondary care services, other than the inclusion of a clinical psychologist in the envisaged networks, no detailed working arrangements are described.

The Vision for Change document identifies the need to build mental healthcare capacity within primary care through enhanced primary care mental health resources, as well as through education and training initiatives, and it recommends the consultation-liaison model in order to achieve greater integration with specialist mental health services. However, at present there is no specific guidance available to either the newly formed PCTs or to existing mental health services in how to pursue these goals. In a worsening economic climate both services can be seen as entering unknown territory without a road-map and both services may have an understandable anxiety as to whether the goal of improved mental health for the population as a whole can be delivered without compromising the quality of service provided to society's most vulnerable individuals. ${ }^{6}$

\section{Opportunities}

Among the arguments in favour of increasing mental health capacity in primary care, the most cogent relates to the high prevalence of common mental disorders in the community. ${ }^{7,8}$ Depression and anxiety disorders in particular have a major public health impact and make a large contribution to the estimated $€ 3$ billion annual economic cost nationally that derives from mental health problems. ${ }^{9}$ International evidence as well as Irish research suggests that one quarter to one third of primary care patients are likely to have clinically significant mental health problems - only a small proportion of which are referred on to specialist care..$^{10,11}$

A recent national survey suggested that the vast majority of adults in Ireland see their GP as the professional contact of choice when they have a mental health problem. ${ }^{12}$ Primary care, therefore, is best positioned to make a positive impact at a population level. The added advantages of primary care as a locus for mental healthcare include familiarity with the patient's general health status over time, continuity in the therapeutic relationship and an acceptable and relatively stigma free treatment setting.

A further justification for enhancing primary mental health capacity relates to evidence of considerable overlap of physical and mental disorders and increasing concerns regarding the general health status of people with major mental illness. ${ }^{13}$

\section{Challenges}

Despite the advantages there are also considerable 
challenges associated with effective delivery of primary mental healthcare. Significant social and economic barriers exist for many people with mental health problems in accessing primary care, particularly for certain sub-groups in society. ${ }^{14}$ For those that do present, the current level of under-resourcing is such that most patients are not offered guideline-recommended interventions in terms of psychological therapies and pharmacotherapy. ${ }^{15}$ Response to first-line anti-depressant treatment, for example, is often poor and many patients who respond do not achieve remission and experience chronic residual symptoms and functional impairment. ${ }^{16}$

In considering the question of how best to plan for an adequate response to the mental health needs of the community an important concept has emerged in recent years - that of primary care mental health which has been defined by the World Health Organisation as incorporating two main elements: ${ }^{17}$

- First-line interventions that are provided as an integral part of general healthcare

- Mental healthcare that is provided by primary care workers who are skilled, able and supported to provide mental healthcare services.

This definition is important and useful for several reasons. Firstly, it places a clear expectation upon primary care to deliver mental healthcare services as a part of general healthcare. From a consumer perspective, this recognises the rights of people with common mental health problems to seek and obtain a response within primary care that is equivalent to that offered to patients with common physical illnesses. Secondly, it acknowledges that the expectation that primary care professionals provide mental healthcare can only be regarded as reasonable if they are provided with appropriate skills and are adequately supported in their efforts. Thirdly, it recognises implicitly that specialist mental health services can complement but not substitute for primary mental healthcare integrated with other primary care health and social services.

\section{What works?}

We have some indication of what works in increasing the mental health capacity of primary care but perhaps more information on what does not work. Screening for common mental disorders, dissemination of treatment guidelines, educational programmes to increase the clinical skills of primary care professionals and adding mental health professionals to primary care teams - so called 'bolt on' approaches - have been well received by the professionals involved. However they do not, on their own, improve patient outcomes. ${ }^{18,19}$ The greatest evidence of clinical benefit and longer-term cost-effectiveness comes from a large number of successful RCTs of collaborative care programmes, mostly carried out in North America, based on chronic disease management principles and focussed on the process as well as the content of interventions. ${ }^{20-22}$

The most important ingredients in the success of collaborative care approaches appear to be the use of a case manager working with the primary care professionals to serve an identified patient group based on clear clinical criteria supported by standardised symptom scales, and with regular supervision provided by a mental health specialist - usually a consultant psychiatrist, within in a stepped care model. ${ }^{15}$ One of the outstanding questions surrounding such programmes, however, is the extent to which they can be successfully replicated in health systems that may differ markedly from those in which they were initially evaluated.

It is also clear that successful implementation requires significant initial investment in human resources in primary care and in the re-engineering of existing service delivery systems so that the interface between primary and secondary care is effectively managed. ${ }^{23}$ Specific skill development is required not only for primary care professionals, but also for mental health specialists whose previous training and experience may not have prepared them for an expanded liaison role. ${ }^{24}$

In the relative absence of available generalist mental health services in the community, the burden of primary mental healthcare has historically fallen to Irish GPs despite considerable time constraints, limited specific training in mental health and few formal arrangements for liaison and support from specialist mental health colleagues. ${ }^{11} \mathrm{GPs}$ have also played a key role as gate-keepers to publicly-funded mental health services, usually through the traditional referral letter. However, as in other countries, where on-site, face-to-face liaison contacts are offered, Irish GPs have been shown to welcome such assistance. ${ }^{25,26}$ They also value quality initiatives which facilitate early access to specialist interventions for people with major mental illness. ${ }^{27,28}$

\section{Shaping a better future}

At this point in the evolution of both primary care and specialist mental health services there is an increasing recognition of the benefits of collaboration. Irish GPs and psychiatrists, as key clinical decision-makers, have a particular challenge and opportunity - in partnership with service users and other professional disciplines - to shape the development of primary care mental health in the newly-formed PCTs and networks, while designing clinically effective and mutually acceptable professional working arrangements between primary and secondary care.

Strong leadership will be required in ensuring that the envisaged new structures for multidisciplinary primary care deliver an actual increase in the mental health capacity of primary care and do not result merely in increased case finding for an already under-resourced specialist mental health service. In an increasingly competitive healthcare environment, now is surely a time for joint advocacy for specific additional investment in professional training and resources which reflect evidence-based practice internationally, and which are properly evaluated to ensure transferability to the unique context of the Irish health system.

A Joint Forum on Mental Health has been recently set up by the Irish College of General Practitioners and the College of Psychiatry of Ireland as one initiative which hopes to harness collaborative leadership in both professional disciplines. The Forum welcomes input from the broad membership of both colleges. It seeks to advance the goal of providing a mental health service to the community which is accessible and equitable in terms of the relative needs of people with common mental disorders and those with major mental illness, so that services to both groups are enhanced without compromising quality to either. 


\section{Declaration of interest: None.}

References:

1. Transformation Programme 2007-2010: Health Service Executive; 2006.

2. Primary Care - A New Direction. Dublin: Government Stationary Office; 2001

3. A Vision for Change - Report of the Expert Group on Mental Health Policy. Dublin:

Government Publications Office; 2006.

4. What we Heard - A Report on the Service User Consultation Process: Expert Group on Mental Health Policy, Department of Health and Children; 2004a.

5. Quality in Mental Health - Your Views. Report on Stakeholder Consultation on Quality in Mental Health Services. Dublin: Mental Health Commission; 2005a.

6. From Vision to Action? An Analysis of the implementation of A Vision for Change. Dublin: Mental Health Commission; 2009.

7. Demyttenaere K, Bruffaerts R, Posada-Villa J. Prevalence,severity and unmet need for treatment of mental disorders in the WHO Mental Health Surveys. JAMA 2004; 291: 2581-2590

8. Golden J, Conroy R, Bruce I, Greene E, Kirby M, Lawlor B. Loneliness, social support networks, mood and wellbeing in community-dwelling elderly. Int J Geriatr Psychiatry 2009; 24(7): 694-700.

9. O'Shea E, Kennelly B. The Economics of Mental healthcare in Ireland. Dublin: Mental Health Commission; 2008

10. Ustun T, Sartorius N. Mental IIIness in General Health Care: Wiley; 1995.

11. Copty M, Whitford D. Mental health in general practice: assessment of current state and future needs. Ir J Psych Med 2005; 22(3): 83-86.

12. Mental Health in Ireland: Awareness and Attitudes. Dublin: National Office for Suicide Prevention; 2007.

13. Thakore J. Metabolic syndrome and schizophrenia. Br J Psychiatry 2005; 186 : 455-456.

14. Russell V, Gaffney P, Collins K, Bergin A, Bedford D. Problems experienced by young men and attitudes to help-seeking in a rural Irish community. Ir J Psych Med 2004; $21(1): 6-10$

15. Katon W, Unutzer J, Simon G. Treatment of depression in primary care: where we are, where we can go. Medical Care 2004; 42(12): 1153-1157.

16. Paykel $E$, Ramana $R$, Cooper $Z$, et al. Residual symptoms after partial remission: an important outcome in depression. Psych Med 1995; (6): 1171-1180.

17. Policies and Practices for Mental Health in Europe: Meeting the Challenge: WHO Europe; 2008.

18. Gask L, Gilbody S, Kendrick T. Improving the quality of primary care mental health: what does and does not work? In: Gask L, Lester H, Kendrick T, Peveler R, eds. Primary Care Mental Health. London: RCPsych Publications; 2009.

19. Tylee A, Walters $P$. We need a chronic disease management model for depression in primary care. Br J Gen Pract 2007: 57(538): 348-350.

20. Russell V, Igoe G. Collaborative care for depression: the case for integrating primary care and mental health services. Irish Psychiatrist 2007; 8(1): 13-17.

21. Bower $P$, Gilbody $S$, Richards $D$, et al. Collaborative care for depression in primary care. Making sense of a complex intervention: systematic review and meta regression. Br J Psychiatry 2006; 189: 484-493.

22. Kates N, Mach M. Chronic disease management for depression in primary care: a summary of the current literature and implications for practice. Can J Psychiatry 2007; 52(2): $77-85$.

23. Richards D, Bower P, Gilbody S. Collaborative care and stepped care: innovations for common mental disorders. In: Gask L, Lester H, Kendrick T, Peveler R, eds. Primary Care Mental Health. London: RCPsych Publications; 2009: 395-409.

24 . Wright $B$, Russell V. Integrating mental health and primary care services: a challenge for psychiatric training in Ireland. Ir J Psych Med 2007; 24(2l): 71-74.

25. Russell V, McCauley M, MacMahon J, Casey S, McCullagh H, Begley J. Liaison psychiatry in rural general practice. Ir J Psych Med 2003; 20(2): 65-68.

26. Jeffers A. Mental Health Services in Primary Care: What do health professionals believe is the best model of care? In: Minding the Gap: The Boundaries and Interface between Psychiatry and Primary Care. College of Psychiatry of Ireland Spring Conference, Cork, 2010.

27. McCauley M, Bergin A, Bannon H, McDonald B, Bedford D, Russell V. How do GPs experience home-based treatment for acute psychiatric disorders? Primary Care \& Community Psychiatry 2005; 10(4): 159-163.

28. Gavin B, Cullen W, O'Donoghue B, Ascencio-Lane JC, Bury G, O'Callaghan E. Schizophrenia in general practice: a national survey of general practitioners in Ireland. Ir J Med Science 2005; 174(3): 38-43. 